\title{
O cotidiano e o viver no Serviço Residencial Terapêutico
}

\author{
Daily activities and living at a Therapeutic Residential Care Center
}

El día a día y el vivir en el Servicio Residencial Terapéutico

Luciane Prado Kantorki ${ }^{1}$, Jandro Moraes Cortes ${ }^{2}$, Ariane da Cruz Guedes ${ }^{3}$, Beatriz Franchini ${ }^{4}$, Daiane de Aquino Demarco ${ }^{5}$

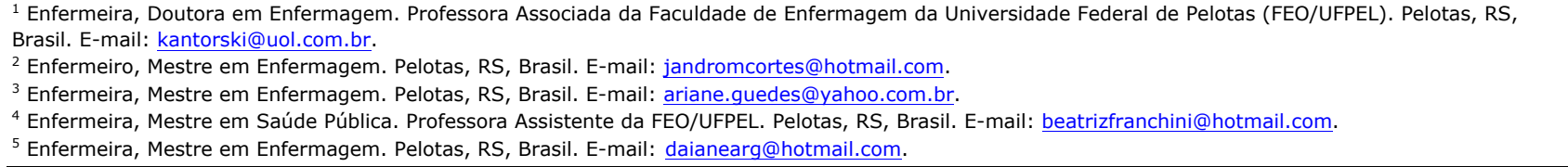

\section{RESUMO}

Objetivou-se descrever e analisar questões referentes ao dia a dia num Serviço Residencial Terapêutico (SRT) e as características da vida cotidiana dos moradores. Trata-se de um estudo de caso realizado em Caxias do Sul, fundamentado na avaliação de quarta geração, conjuntamente com a Metodologia de Análise de Redes do Cotidiano. A partir dos achados, emergiram as categorias: possibilidades no território, participação e flexibilidade nas tarefas da casa, situações que marcam o viver, mediadores colaboradores na resolução de conflitos, a equipe é comprometida com o morador, a liberdade como instrumento terapêutico, dificuldades no cotidiano, construção de alianças. Este estudo contribuiu para conhecer a estrutura do cotidiano vivenciado pelos moradores, desse modo, identificando algumas dificuldades enfrentadas e os mecanismos utilizados para superá-las, além de evidenciar que os profissionais podem ser entes fundamentais no fortalecimento de um cotidiano que pode ser pluralizado, movimentado e enriquecido, sem deixar de respeitar a singularidade de cada morador.

Descritores: Saúde Mental; Serviços de Saúde Mental; Avaliação de Serviços de Saúde; Enfermagem Psiquiátrica.

\section{ABSTRACT}

This study describes and analyzes day-to-day issues in a Therapeutic Residential Care Center and the daily life characteristics of its residents. This case study was conducted in Caxias do Sul, based on an evaluation of the fourth generation together with a Methodology for Analyzing Everyday Life Networks. The following categories emerged: possibilities in the territory, participation and flexibility in household tasks, situations that mark living, employees who are mediators in conflict resolution, staff committed to the resident, freedom as a therapeutic tool, difficulties in daily life, and building of alliances. This study helped to get to know the structure of everyday life experienced by the residents, identifying some difficulties they face and the mechanisms used to overcome them, in addition to noticing that the professionals can be instrumental in strengthening a daily living that can be pluralized, busy, and enriched, while still respecting the uniqueness of each resident.

Descriptors: Mental Health; Mental Health Services; Health Services Evaluation; Psychiatric Nursing.

\section{RESUMEN}

Se objetivó describir y analizar cuestiones referentes al día a día en un Servicio Residencial Terapéutico (SRT) y características del cotidiano de los residentes. Estudio de caso realizado en Caxias do Sul, fundamentado en la evaluación de cuarta generación, conjuntamente con la Metodología de Análisis de Redes del Cotidiano. De los hallazgos surgieron las categorías: posibilidades en el lugar, participación y flexibilidad en tareas hogareñas, situaciones que marcan el vivir, mediadores colaboradores en solución de conflictos, el equipo está comprometido con el residente, la libertad como instrumento terapéutico, dificultades cotidianas, construcción de alianzas. Este estudio contribuyó a conocer la estructura del día a día experimentado por los residentes, identificando algunas dificultades enfrentadas y los mecanismos utilizados para superarlas, además de evidenciar que los profesionales pueden constituir entes fundamentales en el fortalecimiento de un cotidiano quizás pluralizado, dinámico y enriquecido, sin dejar de respetar la individualidad de cada residente.

Descriptores: Salud Mental; Servicios de Salud Mental; Evaluación de Servicios de Salud; Enfermería Psiquiátrica. 


\section{INTRODUÇÃO}

Com a Reforma Psiquiátrica ocorreram transformações da atenção em saúde mental no campo assistencial, com a construção de novos caminhos e ações transformadoras. Assim, surge em fevereiro de 2000 a Portaria no 106/2000, propondo a criação de Serviços Residenciais Terapêuticos como uma estratégia de inserção social das pessoas com transtorno mental ${ }^{(1)}$.

O Serviço Residencial Terapêutico (SRT) ou residência terapêutica, e ainda "moradia", são casas que se localizam na zona urbana criadas para suprir as necessidades de moradia de pessoas com transtorno mental grave que estavam ou não institucionalizadas. Dentre os que podem se beneficiar não estão apenas as pessoas egressas de internação psiquiátrica, mas também pessoas em acompanhamento nos Centros de Atenção Psicossocial (CAPS) onde a equipe de referência identifica problemas relacionados à moradia, e para moradores de rua que são acompanhados nos CAPS, por serem portadores de transtorno mental severo. A casa pode abrigar um único indivíduo ou mais pessoas, não podendo exceder oito usuários por domicílio, sendo que estes contam com suporte profissional para atender às suas necessidades e demandas ${ }^{(2)}$.

É necessário que se explore conceitualmente os sentidos dos vocábulos lar, moradia, residência ou casa. Cabe enfatizar que uma casa no sentido de uma moradia, seria o espaço físico que a arquitetura nos proporciona, já uma casa no sentido de um lar, seria um lugar onde as nossas intimidades encontram abrigo ${ }^{(3)}$.

Importante destacar que os SRT, ao mesmo tempo em que são equipamentos pertencentes a uma rede de serviços de saúde, tem peculiaridades que os tornam diferentes dos outros dispositivos. Outrossim, denota uma vivência na mais ampla significância que o termo possa assumir, de transição entre um equipamento, em termos formais, e de uma casa no sentido de lar. Numa palavra, é um dispositivo em movimento. É neste espaço onde e quando a vida acontece que o cotidiano se desenvolve se (re)inventa, se (re)significa.

As residências nesse sentido são espaços que podem produzir subjetividades e ampliar o olhar numa perspectiva subjetiva de encontro ou desencontro de afetos e trocas, extrapolando os limites físicos da casa, introduzindo-se no território, onde de fato possamos nos "sentir em casa"(3).

$\mathrm{Na}$ literatura são escassos os estudos que privilegiam o cotidiano e o viver de moradores de serviços de saúde mental no contexto da Reforma Psiquiátrica Brasileira, especialmente os que se referem às habitações comunitárias ${ }^{(4)}$. A experiência canadense tem sido relatada(5), mostrando que em Quebec as moradias são do tipo residência familiar, contando com um cuidador e com a supervisão de um gerente de caso, numa relação estreita entre a casa e uma equipe hospitalar multidisciplinar.

O referido estudo ${ }^{(5)}$ chama a atenção para o fato de que os cuidadores não têm formação profissional alguma (e geralmente são mulheres) para não tirar a essência doméstica do morar, constituindo-se este equipamento na primeira opção de moradia para aqueles que saem dos hospitais psiquiátricos. Essas mulheres cuidadoras podem abrigar até nove moradores em suas casas. A pesquisa ainda destaca que é preciso haver flexibilidade nas regras e respeito à particularidade de cada caso, no sentido de que para uns morar só favorece a autonomia, porém para outros pode levar ao isolamento social e à solidão. O passo inicial na recuperação de pessoas com doença mental grave, por meio da habitação- na transição da condição de cliente de um serviço para uma condição de cidadão- o seu cotidiano precisa ser permeado por trabalho e educação, sem uma proteção excessiva dos cuidadores em todos os domínios da vida $^{(5)}$. Todavia, há lacunas nos estudos no que diz respeito a compreensão da estrutura cotidiana da vida das pessoas, ou de que forma elas experimentam o processo de viver nestes espaços.

Nesse contexto torna-se relevante a realização deste estudo com o intuito de despertar reflexões e problematizar as questões que envolvem o cotidiano nesses serviços substitutivos, que são essenciais à produção de novas formas de cuidado no âmbito da saúde mental no Brasil. Assim, este artigo teve como objetivo analisar o cotidiano dos moradores de um Serviço Residencial Terapêutico (SRT).

\section{MÉTODOS}

Trata-se de um estudo de caso, fundamentado na avaliação de quarta geração(6), na perspectiva construtivista, responsiva e com abordagem hermenêutico-dialética, conjuntamente com a Metodologia de Análise de Redes do Cotidiano.

O cenário deste estudo constitui-se em um SRT localizado em Caxias do Sul. A origem deste serviço data do início de 2005, após a intervenção do Ministério Público, em uma instituição asilar no município, que destinava-se a albergar idosos. O Ministério Público então, impele à gestão municipal a criação do SRT, para atender a demanda destas pessoas que tiveram seus 
cotidianos capturados por longos anos de internação psiquiátrica.

O SRT que é cenário deste estudo abriga 11 moradores. Conta com uma equipe multiprofissional composta por dois enfermeiros (sendo um deles coordenador do serviço), técnicos de enfermagem, duas psicólogas, uma terapeuta ocupacional, uma cozinheira, e uma auxiliar administrativa.

Em termos estruturais o SRT localiza-se numa região privilegiada do centro de Caxias do Sul, sendo um prédio nos moldes da arquitetura italiana, com grades cercando todo o seu entorno, contando com interfone, pintado em cores brandas, sendo as aberturas protegidas por grades, um quintal de tamanho mediano e jardins arborizados. Avizinha-se de uma grande escola particular, próximo a dois hipermercados, defronte a uma padaria, perto de uma lotérica, hotéis, rodoviária da cidade e próximo a muitas lojas comerciais ${ }^{(7)}$.

Os instrumentos de coleta de dados foram entrevistas semiestruturadas com equipe de cuidadores/trabalhadores (15) e moradores (11) definidos como grupos de interesse para compor o círculo hermenêutico-dialético, a realização de um grupo de validação com os moradores, e a observação participante de campo (700 horas), configurando-se numa etnografia prévia. A coleta de dados ocorreu no mês de maio de 2010 .

O grupo de validação foi realizado com os moradores, e ocorreu nas dependências do próprio SRT em dia e hora previamente agendados. Neste grupo, foi apresentado uma síntese de todas as entrevistas realizadas, acrescidas dos achados que emergiram da observação participante. Após a exposição desta síntese pelos pesquisadores, os moradores negociaram os pontos de tensionamento, que implicam em seus cotidianos e no seu viver no SRT.

Logo após a coleta dos dados, estes foram organizados, e transcritas as entrevistas, as negociações com os grupos de interesse e as observações de campo. Após, foram agrupadas as unidades de informação que deram origem às categorias analíticas. O Projeto de Pesquisa foi apreciado e aprovado pelo Comitê de Ética e Pesquisa da Faculdade de Odontologia da Universidade Federal de Pelotas, sob o parecer no 073/2009. Os entrevistados concordaram em participar da pesquisa mediante a assinatura do Termo de Consentimento Livre e Esclarecido.

No decorrer do texto, os moradores são identificados pela letra " $\mathrm{M}$ ", os cuidadores pela letra " $\mathrm{C}$ " e os dados provenientes das observações participantes pelas letras
"DC", seguida do número correspondente à entrevista ou à observação. Todo o processo de negociação com os grupos de interesse ocorreu em data e horário previamente acordado, havendo um comparecimento da maioria dos entrevistados.

\section{RESULTADOS E DISCUSSÃO}

Os resultados a seguir revelam como os moradores se sentem ao viverem a cotidianidade no SRT que encontra-se mergulhado num território. Pode-se dizer que a maioria dos moradores fazem colocações que qualificam o espaço do SRT. Entende-se que a positividade em relação ao SRT, pode ser considerada como mediadores colaboradores, pois favorecem para diminuir eventos conflitivos, possibilitando situações que propulsionam os moradores a irem adiante, com o auxílio de uma equipe de profissionais comprometida com o morador.

Viver numa casa e participar das tarefas que integram esta casa, ser protagonista de situações que marcam a vida cotidiana deste lugar, provar da liberdade como instrumento terapêutico e experimentar diversos dispositivos que podem auxiliar o cotidiano, não subtraem algumas dificuldades que precisam ser enfrentadas, e por conseguinte, construir alianças para o enfrentamento necessário, foram elementos e eventos verificados no dia a dia dos moradores do SRT.

A partir destes achados, fundamentado na avaliação de quarta geração, conjuntamente com a Metodologia de Análise de Redes do Cotidiano, síntese dos dados coletados, validados e negociados a partir das entrevistas e observação participante, emergiram as seguintes categorias:

\section{Participação e flexibilidade nas tarefas da casa}

O SRT Caxias do Sul mantém uma rotina diversificada, considerando horários estabelecidos para as refeições, mas com possibilidade de acolher (chamar, negociar) possíveis atrasos. Também há um rol de atividades formais como a equoterapia, o Programa Brasil Alfabetizado, hidroginástica e natação, que se agregam ao cotidiano de todos nós como alimentar-se, dormir, conversar sobre o dia a dia, tendo inclusive o direito de atrasar-se ou, simplesmente, não querer fazer nenhuma atividade.

Para a cozinha [...] Na sala de TV - C(2)5 separa roupas limpas dos moradores, todas as roupas são identificadas. Funcionária da Limpeza: limpa os vidros no final do café. Outro funcionário limpa o chão da cozinha. Chega um 
morador [atrasado para o café] a C(2)11 diz carinhosamente: "Oh meu querido [e passa a mão no cabelo] onde você estava? - Eu te chamei, você não ouviu... Vamos ali sentar e tomar o lanche" [e ajuda-o a levar o lanche até a mesa] [DC4].

A funcionária da cozinha usa máscara e toucas descartáveis e me explica que todos participam de uma escala no auxílio à cozinha, secando louças, nos finais de semana tendo uma escala de culinária, quando participam de pequenas atividades domésticas na cozinha, limpeza das mesas e dos banheiros, muito embora depois de realizadas as tarefas, as funcionárias limpem, se necessário [DC3].

Os moradores do SRT, sujeitos no cenário deste estudo, são em sua maioria, pessoas egressas de longa internação em hospital psiquiátrico. Desse modo, tornaram-se desprovidas de valores, de liberdade de escolha e autonomia, reprimindo qualquer expressão de subjetividade e cidadania. Além disso, o cotidiano deixou de se desenvolver ao lado de suas famílias, para acontecer dentro das rotinas de um hospital psiquiátrico.

Para estas pessoas que tiveram parte de suas vidas dentro de uma instituição psiquiátrica, neste momento viverem e conviverem neste equipamento substitutivo de saúde mental, surge como uma nova perspectiva de vida, já que este serviço almeja estimular a autonomia das pessoas, reinserindo-as na sociedade, de forma que se aproxime do contexto de uma casa, com estabelecimento de relações com todos os que ocupam este espaço, e em constante relação com o território no qual está encravado. Portanto, torna-se ator da comunidade e protagonista da sua própria história e da sociedade, num contexto de relações amistosas ou desarmônicas.

Entende-se o cotidiano como aquilo que se faz, aquilo que acontece e se sucede no dia a dia das pessoas $^{(8)}$. O dia a dia dos moradores do residencial terapêutico se desdobra em um território simbólico, onde traços identitários são construídos, configurando modos de pensar e se relacionar com o acaso, com a diferença, com a loucura. Estar inserido numa dada sociedade é organizar a vida cotidiana de tal forma que ela seja capaz de conduzir a uma continuidade, em interação com as pessoas ao nosso redor e com o modo de produção desta sociedade ${ }^{(9)}$.

O cotidiano ou a vida cotidiana no contexto do SRT passa a assumir uma significância primordial, ultrapassando o que puder ser mais um recurso terapêutico na condução de pessoas com doenças mentais, "mas antes a criação de um espaço de reconstrução de laços sociais e afetivos para aqueles cujas vidas encontravam-se confinados no mundo asilar"(10).

É a partir desta concepção de cotidiano que se pretende apresentar o residencial terapêutico. Há no residencial funcionários que têm a função de limpar, cozinhar, ser acompanhante terapêutico, mas também há espaço programado para inserção dos moradores nas tarefas da casa, sendo presente a preocupação de que este seja um espaço de aprendizado de hábitos diários do viver em uma casa, relacionamentos, trocas e convivência.

Neste contexto de vida diária, de tarefas que todos temos que executar e/ou gerenciar em nossas rotinas dentro do lar, a equipe dos profissionais surge como um elemento importante de apoio e como um mediador colaborador no processo reabilitador, pois está atenta e participa de forma ativa nos acontecimentos que envolvem o dia a dia dos moradores. Sendo assim, onde quer que se encontre o indivíduo, pode haver um trabalho a executar que incide diretamente sobre o habitar. Cabe ao técnico, a função de "estar com". Juntos, na intermediação das ações, nos contextos e relações.

O cuidado ofertado pelo SRT proporciona aos sujeitos um cotidiano mais dinâmico, com independência, no qual essas pessoas participam e realizam tarefas domésticas, compras, pagamentos, além de outras atividades no seu dia a dia. Por isso, as residências possuem uma lógica de cuidado que é produzida na casa, ou a partir da casa, quer seja na rua, supermercado, cinema, escola ou vários lugares do território, pois o foco desse modo de cuidar promove chances de resgate de vida e reconhecimento enquanto sujeito $^{(11)}$.

Em relação às dificuldades cotidianas da vida social, chama-se de "mortificação do eu" o fato de o indivíduo perder sua identidade social frente ao seu mundo doméstico, havendo uma subtração do seu eu social, e uma perda de aprendizagem do convívio na sociedade fora do asilo(12).

Nesse sentido, fica evidente a necessidade da construção de um olhar atento e sutil sobre o dia a dia da vida das pessoas. Assim, um desafio do SRT seria proporcionar encontros "aumentativos de potência", que produzissem liberdade, vida, circulação desses moradores na vida cotidiana, e que ocorra de modo espontâneo para além e aquém das ações dos profissionais de saúde ${ }^{(13)}$. 


\section{Situações que marcam o viver}

No território em que se insere o SRT em seu dia a dia são geradas personalidades, capacidades, comportamentos desenhados a partir de uma oferta de vivências, enriquecida pela possibilidade de se expor continuamente à complexidade que é conviver em espaços, tempos, com pessoas diferentes, em situações que marcam o viver das pessoas comuns e permitem organizarem a vida cotidiana, permitindo a expressão de subjetividades, como expresso a seguir:

Durante o almoço verifico que são utilizados pratos e copos de vidro, a comida é servida por um técnico de enfermagem [C(2)11] para aqueles moradores que não conseguem servirem-se sozinhos e mais a vontade à medida que tem mais autonomia para tanto. [...] Participam do almoço as três auxiliares de enfermagem e o enfermeiro. Os usuários conversam calmamente durante o almoço e há comida derramada no chão. M(2)16 conversa com a outra moradora sobre a aula de Alfabetização na parte da tarde. Pós almoço são estimulados a limparem suas mesas e logo após escovarem os dentes. Depois de a moradora $X$ acabar de limpar as mesas a funcionária da limpeza completa o trabalho [DC(2)3].

O cotidiano é identificado com o território, enquanto espaço e tempo. Resulta de um processo de socialização, de dada interação entre indivíduo e grupo, ele gera personalidades, capacidades e comportamentos diferentes de indivíduo para indivíduo, enfim, transforma o espaço em um lugar simbólico, em que o indivíduo age e torna humana a sua vida ${ }^{(14)}$.

As descrições deste espaço-momento na casa faz-se mister que se imagine o que é afinal necessário para que se construa uma casa, um lar efetivamente, respeitando e acolhendo as diferenças mais sutis entre cada morador, que também é elemento constitutivo deste $\operatorname{lar}^{(10)}$. Logo, uma casa é composta por pessoas, cômodos, cozinha, banheiros, quartos, uma sala de estar, um quintal, além de mesa, cadeira, panelas, garfos, quadros, enfeites, enfim tudo o que uma casa precisa, e desta forma os espaços antes vazios vão sendo preenchidos, e a casa vai se formando, afinal um lar é feito também de detalhes.

E uma casa se localiza em um bairro, que por sua vez está em uma comunidade, e esses moradores rumam a este bairro geográfico, na vida concreta, fazendo parte deste meio social, tendo de aprender a conquistar esta casa como seu espaço doméstico e abandonar a vida passiva imposta pela institucionalização. A vida cotidiana não está fora da história, mas no "centro" dela. Assim, a vida social, política, econômica são gestadas e colocadas em prática no cotidiano, e deste modo a autora chama o cotidiano de heterogêneo, referindo-se aos diversos aspectos da vida que constituem e modificam os modos de realização de nossa humanidade no cotidiano, como as relações familiares, de trabalho, a vida privada, o descanso e o lazer, as relações de gênero, de etnia e a construção das identidades ${ }^{(9)}$.

Desse modo, o SRT tem se revelado como problematizador da atenção em saúde mental, já que tem a capacidade de mobilizar questionamentos relativos aos modos de morar e habitar neste serviço, que também é uma casa para os moradores ${ }^{(13)}$.

\section{Mediadores colaboradores na resolução de conflitos}

Nas relações cotidianas há necessidade de construir saídas e alianças frente aos conflitos que aparecem. Os fragmentos abaixo mostram os laços fortes formados entre os moradores, constituindo-se como mediadores colaboradores na resolução de conflitos:

[Viver no SRT] é bom se dando com os colegas está bom. Porque a gente faz o que a gente quer, cada dia um faz o almoço, que nem hoje eu limpei o banheiro e a cozinha e a M(2)1 fez o almoço, é um dia cada um... É bom que nem a gente sai que nem domingo vamos almoçar fora... No restaurante aqui perto [M12].

Cada um faz as suas coisas, a roupa, por exemplo, minha roupa e tem a máquina lá atrás eu lavo [M3]. Aqui dentro é bom, tem dia que a gente briga, mas a gente conversa se entende... Eu gosto daqui, eu gosto daqui eles [falando dos moradores] são bons para mim eu também sou [M1].

Nesse modo de construção de vida e de interação entre as pessoas surgem mediadores que colaboram na resolução dos problemas vivenciados pelos moradores. Neste cotidiano são consolidados valores, atividades, relações, potencialidades dos sujeitos, direitos. Deste modo, os moradores falam sobre como é viver o dia a dia no residencial e sobre os mediadores colaboradores neste contexto. No cenário concreto e subjetivo do SRT, estabelece-se relação entre os moradores e verdadeiros laços familiares.

"Estar em casa" tem a representatividade do direito de ir e vir, da livre escolha do que comer, de como 
vestir-se, do simples fato de poder optar. Constrói a própria apropriação das minúcias, do quando e de que forma executar as coisas. É um espaço de invenção de vida, expressão de subjetividades, socialização, permitindo a potencialização da vida e liberdade ${ }^{(13)}$.

Passear quando ou se quiser, limpar um jardim, comprar mercadorias, descobrir ou redescobrir formas de se relacionar consigo e com outras pessoas, desenvolver um trabalho, seja ele remunerado ou não, fazer amizades, descobrir os direitos, e encontrar um namoro, ter a possibilidade de expressar a sua fé, seja indo à missa ou em um terreiro de umbanda, são estratégias dotadas de um fundamento, um capital simbólico-afetivo que auxiliará a pessoa em sofrimento psíquico a resgatar a sua cidadania, neste movimento interno em direção ao externo, à rua, à vida(15).

\section{A equipe é comprometida com o morador}

A equipe é comprometida com as questões relacionadas ao morador, assim como para viver em uma casa com questões como a administração financeira, do lar ou da própria pessoa. São questões necessárias, através do banco pedagógico e da utilização do afeto como recurso, evidenciadas nos fragmentos abaixo:

Por que eu quero dinheiro toda hora e tem horário que eu recebo só na terça e na sexta, ai eu compro roupa nova [...] a melhor coisa, aprende para depois o cara ter o dinheiro do cara, e direciona ele [M(2)20].

$C(2) 2$ mostra onde guardar o troco. $M(2) 7$ se refere como se o dinheiro não fosse seu e C(2)2 diz: "Não, esse dinheiro não é meu, esse dinheiro é teu" [DC(2)1].

Presencio vocativos afetuosos como "querido" por várias vezes durante o almoço por parte da equipe em relação aos moradores [DC(2)3].

A equipe do SRT pesquisado auxilia os moradores a saber lidar com seu próprio dinheiro, numa estratégia denominada "Banco Pedagógico", na qual a equipe possibilita ao morador controlar o seu dinheiro, que fica guardado junto às dependências dos profissionais da equipe, em repartimentos individuais (armário). Adjunto a ele se encontra um livro-controle que se destina ao registro sistematizado, das despesas e receitas de cada morador, sendo que a cada utilização do dinheiro, seja por necessidade ou pela sua simples vontade, demanda que um dos integrantes da equipe o auxilie a compreender cognitiva e sistematicamente, a situação na qual o dinheiro está sendo gasto de uma forma racional.
Independente da situação e/ou das condições intelectuais deste morador, o procedimento é sempre realizado, o cuidador demonstra em cada situação as formas de controlar, empregar, distribuir de forma equânime o dinheiro, auxiliando o morador e respeitando as preferências individuais de cada um. Neste contexto, novamente a equipe de profissionais surge como importante mediadora colaboradora no cotidiano, auxiliando os moradores na busca pela autonomia.

Além disso, os moradores percebem o afeto que é constantemente dispensado por parte dos profissionais do SRT, sendo uma constante na prática de trabalho, ultrapassando os limites de um simples recurso terapêutico, constituindo-se em um mediador colaborador, no sentido de ser um elemento fundamental na reconstrução dos laços sociais rompidos pelos longos e solitários anos na reclusão do manicômio.

Sugere-se a utilização do afeto pelos profissionais que atuam na saúde mental, podendo utilizá-lo nas dimensões de suas ações como recurso, como base de sustentação para que ancorem a sua prática profissional, estabelecido através de um relacionamento interpessoal com vínculos à reconstrução dos laços fragilizados no manicômio(7).

O trabalho dos cuidadores no SRT tem um enfoque psicossocial, com uma postura mais horizontal e humanizada em relação aos moradores ${ }^{(16-17)}$. O trabalho em saúde mental objetiva dar conta das necessidades de um determinado grupo, tendo uma dimensão social, sofrendo transformações nos diferentes momentos da construção do conhecimento e da vida em sociedade ${ }^{(18)}$. As demandas apresentadas são diversas, necessitando que muitas vezes a equipe reorganize seu processo de trabalho, inventando e reinventando estratégias de intervenção psicossocial para esses grupos.

\section{A liberdade como instrumento terapêutico}

A liberdade é utilizada como instrumento terapêutico, permeando o trabalho da equipe de profissionais. Os trechos abaixo deixam evidente que $o$ direito de ir e vir dos moradores mais do que respeitado é potencializado pelos profissionais, em ocasiões exemplificadas como no caso de ter vontade de deslocarse a uma praia distante ou, pagar por uma massagem numa clínica privada.

Aqui a gente pode ir pra praia, para a piscina de Goiabinha, que fica em São Leopoldo [M2].

Saio com M(2)16, ele tem massagem relaxante uma vez por semana, particular, em uma clínica de estética 
localizada perto da Prefeitura Municipal de Caxias do Sul. M(2)16 faz as saídas sozinho, sem acompanhante [...] Ele me mostra os lugares que ele frequenta, passamos pelo supermercado, por uma Faculdade, onde ocorrem as aulas do Brasil Alfabetizado [DC(2)2].

A liberdade que os moradores têm no SRT é evidenciada de diversas formas, tanto em relação aos lugares que frequenta, quanto ao fato de escolher o que fazer e quando fazer. O sujeito constrói sua vida como decidir e escolhe os caminhos que irá seguir, não importa aonde vai chegar porque a própria escolha é a liberdade. No SRT os moradores têm poder de decisão, diferentemente do que ocorre no hospital psiquiátrico onde não há essa liberdade de escolha.

O SRT se articula com o CAPS, que é um serviço estratégico no processo da RP pelo qual toda a rede de saúde mental se desdobra. No CAPS os moradores participam de diversas atividades como as oficinas terapêuticas, atividades de lazer, deixando claro que a decisão de ir, ou não ir, é do usuário.

A realização de uma atividade como uma oficina terapêutica pode ter por objetivo produzir arte, ter um ganho valorizado, ou simplesmente para o usuário pode ser entendido como um local de aliviar as tensões, ou o que importa é a reunião informal que ocorre antes mesmo da oficina começar, considerando que é um ambiente de encontros possíveis ${ }^{(19)}$.

\section{Dispositivos e formas de cuidar que auxiliam no cotidiano}

Dentre os dispositivos utilizados no cotidiano dos moradores estão espaços como a hidroginástica, hidromassagem, fisioterapia, cinema, passeios no parque, auxílio nas tarefas domésticas, a relação com o sagrado e com a fé tornam-se espaços e momentos de convivência, integrando os moradores de fato a casa e a sociedade que pertencem.

Eu posso sair se eu quiser sair para um passeio, a gente faz passeio, tem os cavalos [referindo-se a equoterapia], tem a hidromassagem, tem o cinema que a gente vai, isso faz parte... Daí o pessoal se reúne, assim faz umas comidas [M(2)11].

[Sobre a hidroginástica] eu pulo, brinco, nado de espaguete, eu brinco com peixinho, eu tento nadar só que afundo... Daí depois a gente faz alongamento, depois da "tchau" para a $X$, daí a gente vem embora, vai para o banheiro, vai trocar de roupas, depois a gente toma banho, passa uma água, depois a gente veste a roupa... Vai eu, o $M(2) 12$ o $M(2) 13 . .$. de vez em quando vai a $M(2) 8 . .$. aquela morena... Fui fazer fisioterapia, era de ficar na água, e depois era de alongamento, e caminhava lá dentro de casa [M(2)9].

C(2)12 comenta que o seu trabalho é contínuo com os moradores, que ela ensina constantemente as tarefas para eles. Que quando a M(2)8 foi trabalhar [realizar as atividades] na cozinha, não sabia nem ao menos pegar a esponja na mão e que hoje lava e seca a louça sem auxílio [DC(2)1].

Sento ao seu lado e $M(2) 6$ começa a conversar. Diz que vai à Igreja $X$, dia sim, dia não, e que já é "batizada nas águas", que foi batizada em um rio. $11 \mathrm{~h}$ - M(2)6 volta da missa, está feliz, diz que tinha gente como nunca tinha visto e que o padre pediu para rezar pelas mães hoje, e que a missa estava muito boa [DC(2)1].

É no cotidiano que se devem construir estratégias de cuidado, é nele que ocorrem os encontros com o drama do existir e com os modos de se habitar no mundo, criando resistência à mesmice ${ }^{(20)}$. O cuidado não é algo isolado do dia a dia do usuário, nem é pautado na inalterabilidade, visto que é nele que se estabelecem as relações, se expressam as subjetividades e dramas da nossa existência. A autonomia é evidenciada no cotidiano através da realização de diversas atividades, sendo que a equipe estimula cada um para que consigam realizar as atividades sem auxílio. Ficam evidenciadas situações nas quais o morador chegou ao serviço sem conseguir realizar as tarefas mais simples, e hoje consegue desempenhar estas atividades e outras que demandam uma maior capacidade.

Com a produção da sua autonomia o sujeito utiliza menos dispositivos assistenciais tanto do serviço quanto da sua rede social, como familiares, amigos, vizinhos, possibilitando assim maior inserção na comunidade. É através dessas relações que o sujeito estabelece suas próprias normas, não se mantendo refém de determinações únicas, sendo capaz de estabelecer relações em qualquer circunstância ${ }^{(21)}$. Neste contexto de desenvolvimento de autonomia, de um sujeito-cidadão, emerge a relação com a fé, sendo um ponto de apoio importante, bastante evidenciado pelos moradores.

Há uma variedade de estudos que permeiam as temáticas de religiosidade e a doença mental, tanto por pesquisadores do campo etnográfico quanto epidemiológico. Na tentativa de encontrar um alívio para o sofrimento ou encontrar uma significação na vida de quem adoece mentalmente, o encontro com a religião e 
com o sagrado parece ser algo marcante no seu contexto de vida ${ }^{(22)}$.

$\mathrm{Na}$ literatura americana, vários estudos evidenciam que a espiritualidade pode influenciar no bem-estar subjetivo por favorecer a integração junto ao suporte social da pessoa. O estabelecimento de relações com o sagrado, signos e símbolos promovem a coerência existencial consigo próprio, ou até mesmo estimulam modos de vida específicos de algumas religiões, influenciando significativamente a qualidade de vida da pessoa que por ventura esteja com uma doença mental ${ }^{(23)}$.

\section{Dificuldades no cotidiano dos moradores}

Apesar do trabalho contínuo da equipe, alguns moradores encontram dificuldades para realizar seus cuidados pessoais e necessitam de auxílio contínuo em seu cotidiano. Outro entrave apontado pelos moradores refere-se à dificuldade de conseguir um emprego formal, como fica evidenciado nos relatos abaixo:

Eu não consigo tomar banho sozinho, eu não consigo... eu não consigo ir ali em cima telefonar sozinho. Tem que esperar tudo [M(2)9]. Quando eu brigo com o meu marido aqui eles me levam pra lá, eles esquecem o horário que eu faço xixi, sabe? Daí eu não levanto e faço xixi na cama, eles me dão banho, me lavam e ficam com a roupa lá e lavam e me devolvem [M1].

A mera saída da instituição psiquiátrica e a chegada ao SRT por si só não garantem à pessoa com transtorno mental a real mudança do modo de vida asilar ao modo de vida cotidiano e doméstico de uma casa. Os moradores, devido aos arrastados e destruidores anos na vida manicomial, podem reproduzir o cotidiano institucionalizante na casa, trancando-se em seus quartos, negando-se a participar das tarefas domésticas, e permanecendo numa situação de profunda passividade à espera de cuidados e tutela a que foram outrora submetidos $^{(11)}$.

Outra dificuldade é a impossibilidade de exercer um trabalho formal, pelo fato de receber o benefício, questão essa que não tira os sonhos e as expectativas de uma profissão.

O cara não pode trabalha porque recebe um beneficio, e se trabalha o cara perde tudo [...] é trabalha eu gostaria, trabalha em cerâmica, faze que não seja de carteira assinada, se não for eu quero [M20].
Vive-se um modelo econômico excludente que proporciona ao morador, agora trabalhador, um sentimento de culpa por estar desempregado ou por este não atender a requisitos impostos por qualificações que ele não dispõe para o mercado, o que pode gerar uma sensação de fracasso e potencializar a baixa autoestima. Assim, esses sentimentos de fracasso trazem consequências que comprometem a saúde mental do morador. Sugere-se a importância de se investigar e traçar um perfil da pessoa desempregada a fim de intervir de forma concreta, minimizando os sentimentos de fracasso, muito embora estes estejam revestidos de vitimização ou culpabilização ${ }^{(24)}$.

As consequências do desemprego podem fragilizar os laços sociais e afetivos, a restrição dos direitos, potencialização de sintomas depressivos, ou incentivar de certa forma a inércia de continuar desempregado. Percebe-se aqui um contexto político paradoxal, pois se por um lado a remuneração oriunda das políticas públicas tem por principal objetivo assegurar a subsistência das pessoas portadoras de doenças mentais, por outro lado o fato de estarem impedidos de exercer uma atividade laborativa formal, pelo risco de perderem o "benefício", gera nos moradores estes sentimentos difusos.

\section{Construção de alianças para enfrentamento de dificuldades no cotidiano}

Os moradores evidenciam ainda a formação de alianças com vistas à construção de saídas, a serem concretizadas através de projetos de futuro relacionados ao trabalho e também com possibilidades de morar sozinho.

Trabalhar é bom, eu gosto [...] faz bem pra saúde da gente trabalhar [...] só que um dia eu queria uma casa daquelas lá pra mim e o meu marido, e o meu sogro [...] nós estamos aqui meu filho, só por passagem, nós não estamos aqui pra sempre [M1].

Acho que é bom, comprar, fazer um empréstimo é bom pra sair daqui [...] morar sozinho [M16].

Com o tempo, morar sozinho... [planeja] Fazer as coisas, mas acho que não sei se vai dá... Já estou acostumado aqui... Com os colegas [M12].

O otimismo nas falas dos sujeitos nos levam a pensar no contexto paradoxal ${ }^{(25)}$ que permeia o SRT, se por um lado o lar configura-se como um espaço terapêutico, por outro remete a um serviço, desta forma unindo objeto e objetivos muito diferentes. Ainda assim, 
é neste espaço que se procura aumentar a capacidade contratual e traçar caminhos para reabilitação em um ambiente de circulação e reconstrução de vínculos ${ }^{(6)}$.

Ademais, percebe-se a fala entusiasmada dos moradores no sentido de terem vontade de ter um trabalho remunerado, de morarem sozinhos, a possibilidade de se relacionarem novamente com seus familiares, de reatarem laços fragilizados, ou criarem outros. Desenvolverem afetos, construírem de forma nova, reinventada, alianças e saídas como pontes que permitam "sair para fora" e (re)construírem uma vida que é construída de sentimentos, desejos, dúvidas, fracassos e fortalezas.

\section{CONCLUSÃO}

O cenário pano de fundo deste estudo tem uma configuração ambígua, transitando ora como um equipamento serviço e outrora como uma casa-lar. Em nosso entendimento esta "ambiguidade" tem sua razão de ser no processo reabilitatório dos moradores deste lugar. Assim, a reconstrução do cotidiano destes moradores desenvolve no usuário-cidadão uma autonomia pautada no poder de decisão que o aproxima do contexto de uma casa, com afetos e conflitos.

A estratégia do Banco Pedagógico aparece como uma ferramenta que empodera os moradores, estimulando sua autonomia e seu poder de escolha. E é neste cotidiano, com uma rotina diversificada, como a participação do Programa Brasil Alfabetizado, as atividades de socialização como a equoterapia e a natação, as múltiplas oficinas oportunizadas pelo CAPS, os passeios, ou então as rotinas mais simples como as tarefas domésticas que executam, que as reconstruções dos laços afetivos e sociais fortalecerão a vida destas pessoas.

Ainda no que se refere aos laços familiares, os moradores referem seu desenvolvimento dentro do SRT, entre moradores e profissionais, quando estes utilizam o afeto como um recurso terapêutico. As relações com o sagrado e com a fé foram evidenciadas pelos moradores, bem como a vontade de trabalhar e morarem sozinhos.

É neste contexto de vida que o cotidiano se desenrola, tendo a equipe de profissionais como principal mediadora e colaboradora do fortalecimento da cidadania do usuário. Na perspectiva de reconstrução dos laços dos moradores, a partir de uma concepção que liberta através da autonomia, os moradores são capazes de reconstruir seu cotidiano, pautado nos desejos de quem nunca deixou de sonhar.

Com relação ao impacto dos resultados apresentados consideramos que este estudo contribuiu para conhecer a estrutura do cotidiano vivenciada pelos moradores de um SRT, identificando algumas dificuldades enfrentadas e os mecanismos utilizados para superá-las, além de evidenciar que os profissionais podem ser entes fundamentais no fortalecimento de um cotidiano que pode ser pluralizado, movimentado e enriquecido, sem deixar de respeitar a singularidade e heterogeneidade de cada morador.

Este estudo de caso insere-se no bojo das pesquisas que avaliam serviços substitutivos em saúde mental, trazendo subsídios singulares para a política de saúde mental, de modo que evidenciou potencialidades e fragilidades do cuidado em liberdade, possibilitando pensar estratégias de avanço.

http://cirrie.buffalo.edu/encyclopedia/article.php?id=236\&langua ge=en.

6. Guba E, Lincoln Y. Effective evalution. SanFrancisco: Jossey Bass Publishers.1998. 423p.

7. Cortes JM. Os laços sociais de indivíduos em sofrimento psíquico. [dissertação]. Pelotas: Faculdade de Enfermagem, Universidade Federal de Pelotas; 2012.

8. Ferreira AB. Mini Aurélio: dicionário da língua portuguesa. 7. ed. Curitiba: Positiva; 2008.

9. Heller A. O cotidiano e a história. São Paulo: Paz e Terra; 2000.

10. Marcos CM. A reinvenção do cotidiano e a clínica possível nos Serviços Residenciais Terapêuticos. Revista Psychê de Psicanálise. São Paulo, 2004;14(8):179-90.

11. Júnior HPOS, Silveira MFA. Práticas de cuidados produzidas no serviço de residências terapêuticas: percorrendo os trilhos de retorno à sociedade. Rev Esc Enferm USP. 2009; 43(4):788-95.

12. Goffman E. Estigma - notas sobre a manipulação da identidade deteriorada. Publicação Original: 1891. Tradução: Mathias Lambert. Data da Digitalização: 2004.

13. Amorim AKMA, Dimenstein M. Desinstitucionalização em saúde mental e práticas de cuidado no contexto do serviço 
residencial terapêutico. Ciênc. saúde coletiva. 2009;14(1):195-

204.

14. Certeau M. A invenção do cotidiano. Artes de fazer.

Petrópolis - RJ: Vozes; 2001.

15. Dalmolin BM. Esperança Equilibrista: cartografias de sujeitos em sofrimento psíquico. Rio de Janeiro: Editora Fiocruz; 2006.

16. Silva DS, Azevedo DM. A Reforma Psiquiátrica na visão de quem cuida: percepções de profissionais do Serviço Residencial Terapêutico. Esc Anna Nery (impr.) 2011 jul-set; 15(3):587-94. 17. Silva DS, Azevedo DM. AS novas práticas em saúde mental e o trabalho no Serviço Residencial Terapêutico. Esc Anna Nery 2011;15(3):602-9.

18. Campos CMS, Soares CB. A produção de serviços de saúde mental: a concepção de trabalhadores. Ciênc. Saúde Coletiva, 2003; 8(2):621-8.

19. Monteiro RL, Loyola CMD. Qualidade de Oficinas Terapêuticas segundo pacientes. Texto Contexto Enferm. Florianópolis, 2009; 18(3):436-42.

20. Yasui S. A atenção psicossocial e os desafios do contemporâneo: um outro mundo é possível. Cadernos Brasileiros de Saúde Mental, 2009;1(1).

21. Moreira MIB, Andrade AN. Habitar a cidade: análise de serviços residenciais terapêuticos. Psicol Soc. 2007; 19(3):46-54. 22. Dalgalarrondo, P. Estudos sobre religião e saúde mental realizados no Brasil: histórico e perspectivas atuais. Rev psiquiatr clín. Suppl 1. 2007; 34: 25-33.

23. Ellison CG. Religious involvement and subjective well-being. Journal for Health and Social Behavior, 1991; 32:80-99.

24. Coutinho MC, Jacques MG. Uma contribuição da psicologia para a análise das implicações do desemprego. Revista Psico, 2004; 35(2):161-7.

25. Rangel MN. A "Nova Cronicidade" nos "Novos" Serviços de Atenção Psicossocial" [dissertação]. Rio de Janeiro: Fiocruz; 2008.

Artigo recebido em 04/03/2013.

Aprovado para publicação em 02/06/2014.

Artigo publicado em 31/12/2014. 